Article

\title{
A Hybrid Personnel Scheduling Model for Staff Rostering Problems
}

\author{
Jiun-Yan Shiau * D , Ming-Kung Huang and Chu-Yi Huang \\ Department of Logistics Management, National Kaohsiung University of Science and Technology, \\ Kaohsiung City 80778, Taiwan; 0328903@nkust.edu.tw (M.-K.H.); z881118@yahoo.com.tw (C.-Y.H.) \\ * Correspondence: sho@nkust.edu.tw
}

Received: 19 July 2020; Accepted: 22 September 2020; Published: 3 October 2020

\begin{abstract}
The problem of staff scheduling in the airline industry is extensively investigated in operational research studies because efficient staff employment can drastically reduce the operational costs of airline companies. Considering the flight schedule of an airline company, staff scheduling is the process of assigning all necessary staff members in such a way that the airline can operate all its flights and construct a roster line for each employee while minimizing the corresponding overall costs for the personnel. This research uses a rostering case study of the ground staff in the aviation industry as an example to illustrate the application of integrating monthly and daily schedules. The ground staff in the aviation industry case is a rostering problem that includes three different types of personnel scheduling results: fluctuation-centered, mobility-centered, and project-centered planning. This paper presents an integrated mixed integer programming (MIP) model for determining the manpower requirements and related personnel shift designs for the ground staff at the airline to minimize manpower costs. The aim of this study is to complete the planning of the monthly and daily schedules simultaneously. A case study based on real-life data shows that this model is useful for the manpower planning of ground services at the airline and that the integrated approach is superior to the traditional two-stage approach.
\end{abstract}

Keywords: personnel scheduling; staff rostering problem; mixed integer programming; aviation industry

\section{Introduction}

Manpower is the most critical resource for most enterprises and determines the delivery capacity of an enterprise as manpower directly affects the available production capacity. Therefore, how to effectively use manpower is often a prerequisite for planning related issues.

The scheduling of airline staff and the assignment of staff to flights (also called staff rostering) are important and difficult planning functions that most airlines undertake on a monthly basis. Solving a rostering problem includes the construction of individualized schedules that consider various pre-assignments (like training or observer flights), as well as staff requests (such as days off or preferred flights). Airline schedule planning normally consists of four major steps [1]:

- $\quad$ Step 1: flight schedule design;

- Step 2: fleet assignment;

- Step 3: aircraft maintenance routing;

- $\quad$ Step 4: staff planning.

Step 2 and 4 of airline schedule planning are associated with airline staff. Some researchers have also considered the airline staff scheduling problem as an airline staff pairing problem and an airline staff rostering problem, which are likely to be solved sequentially. 
Fleet assignment planning (also known as staff pairing) is normally implemented on a monthly basis and forms a monthly staff schedule. The term "pairing" denotes a sequence of flights that originate and terminate at the staff base, satisfy numerous regulatory constraints, and fulfill airline-policy. A pairing is essentially a sequence of flight duties, starting and ending at the same staff base, and must be assigned to one or more staff members working in one or more staff positions (ranks). The objective of the staff pairing subprocess is to minimize staff costs and at the same time, cover all scheduled flights with their necessary staff requirements. In many airline service systems, there is nonstationary demand: the number of customers fluctuates over time according to a stochastic-though to some extent, predictable - pattern. To safeguard the performance of such systems, adequate personnel capacity planning (i.e., determining the appropriate staffing levels and/or shift schedules) is often crucial. The personnel capacity planning process is usually decomposed into four steps [2]:

1. Forecasting demand (based on empirical data).

2. Determining staffing requirements: The staffing levels required over time are selected to meet a specific performance target at minimal cost.

3. Shift scheduling: This step determines how many workers are assigned to each shift type to cover the staffing requirements.

4. Rostering: In this final step, employees are assigned to shifts.

Pairings may differ in length, from one-day, two-sector, short-haul pairings up to 15-day or 16-day multi-sector long-haul pairings.

Staff planning (also known as staff rostering) is normally implemented on a 10 day basis and forms the daily staff schedule. Short-term schedule updates may represent an additional step. Staff rostering focuses on assigning pairings to lines of work and considers the need to provide sufficient rest periods between flights and satisfy regulatory requirements and collective bargaining agreements. The staff rostering process generally aims not only at minimizing the operational costs for the airline company, but also at maximizing the social quality perceived by the staff members. In the United States, these lines of work are then typically assigned to individual staff members through a bidding process in which the staff members bid on their preferred work schedules, provided that they possess the required rank and qualifications.

One drawback is the rigid structure of this approach (i.e., undertaking the airline staff pairing problem and the airline staff rostering problem sequentially) since problems arise when some bid lines cannot be assigned entirely to staff members due to conflicts with pre-assignments and vacation days. The "personalized rostering approach", however, directly constructs individual rosters for each staff member. This approach, which is being increasingly adopted by airline companies, is based on a fair and equal share principle that satisfies certain quality preferences related to workload (e.g., free days and night flying duties).

From a mathematical programming perspective, the complete airline schedule planning system consists of three mathematical models: (1) the Duties Generation Problem (DGP), (2) the Crew Scheduling Problem (CSP) (i.e., staff pairing), and (3) the Crew Rostering Problem (CRP) (i.e., staff rostering) [3].

In this paper, we propose a hybrid personnel scheduling model referred to as integrated rostering, which differs from the above model by considering pre-assignments (e.g., training and observer flights) and staff requests (e.g., days-off, annual leave, and specific flights) when constructing individualized lines of work for each staff member. The primary goal of rostering is to provide a fair and even distribution of the workload among all staff members and to maximize the staff members' aggregated satisfaction with their individual lines of work. When tasks are known at the time of roster generation, assigning tasks and shifts at the same time potentially leads to lower-cost solutions compared to making the assignments sequentially. The proposed approach, for the actual case study, exhibited a significant impact, despite its modeling simplicity. 
This study is different from previous studies in that it uses a mathematical model to integrate and solve the rostering problem of various shift scheduling problems. This research uses a rostering case study of ground staff in the aviation industry as an example to illustrate the application of integrating monthly and daily schedules. The ground staff in the aviation industry case represents a rostering problem that includes three different types of shift scheduling results: fluctuation-centered, mobility-centered, and project-centered planning. The proposed hybrid personnel scheduling model is examined with reference to the ground staff rostering case study.

\section{Literature Review}

This research addresses issues mainly at operational levels and then from operational strategy perspectives. Abernethy et al. [4] proposed a three-tier framework for Personnel Scheduling, involving (1) planning (determining the overall manpower requirements), (2) scheduling (the distribution of working hours based on available manpower), and (3) allocation (the allocation of personnel to the designated operations). Mattia et al. [5] further divided staff scheduling into five major steps: (1) forecasting, (2) staffing, (3) shift scheduling, (4) rostering, and (5) monitoring. Forecasting and staffing can be classified as the planning tier, while shift scheduling is the scheduling tier, and rostering and monitoring can be classified as the allocation tier. Because planning and scheduling are related to the type of business operations, we first discuss them under two extreme scenarios in the service industry and manufacturing. These two extreme scenarios result in two types of shift scheduling results: (1) flexible shifts and (2) fixed shifts.

In the service industry, production (i.e., the provision of services) is performed in direct contact with customers. In a service environment, the service personnel (such as bank tellers and telephone operators) provide some predefined service items to the customers. Although the number of staff for each service item is fixed, the number of service items available at each point in time is dependent on demand forecasts. To achieve satisfactory workforce utilization, companies often deploy their manpower in so-called flexible shifts. A Flexible shift is a working time template that indicates how to allocate the working time (i.e., shifts) of each working day; each shift (Shift) will also have a continuous and fixed period (usually $8 \mathrm{~h}$ per working day). Therefore, the manpower planning problem in the service industry is mainly located in the design of flexible shifts that can meet certain optimization performance indicators (e.g., labor costs).

The manufacturing industry is different from the service industry. Generally, the manufacturing industry usually adopts a fixed and continuous time shift mode (i.e., Fixed Shifts) (for example, morning shift, lunch shift, and night shift). The largest difference from the service industry is that demand forecasting is indirectly related to the use of manpower. The use of manpower in manufacturing is more closely related to the production plans of an enterprise, so it is often regarded as one of the resources required for the production plan. Thus, some scholars classify manpower planning under production scheduling. Therefore, the importance of manpower planning in manufacturing is often ignored.

\subsection{Types of Personnel Scheduling Problems}

The complexity of staff scheduling varies according to different scheduling issues. According to different scheduling methods, Morris and Showalter [6] distinguished the mathematical programming problems for personnel scheduling into three broad categories:

- Shift Scheduling Problems: Planning a daily shift schedule to arrange and decide at what time of day employees need to go to work. The simplest method is to assign non-overlapping shifts. Although non-overlapping shifts can meet the demands during peak hours, they always produce a waste of personnel during off-peak hours.

- The Days-off (days-on) Scheduling Problem: This scheduling problem is planned on a weekly basis and the needs of employees are known every day. When a vacation is confirmed, the employee's working days can be known. There are many types of vacations. For example, one day or two 
days of vacation can be taken during the week; vacations can also be divided into continuous vacations and discontinuous vacations.

- The Tour Scheduling Problem: Each planned shift schedule is based on one week and the schedule includes vacation days and working hours. Thus, the scheduling problem for vacation duty is a combination of the scheduling problem of the duty shift and the scheduling problem of vacation duty. Therefore, the problem of shift type becomes very significant and much more difficult to solve.

Ernst et al. [7] noted that most personnel scheduling starts with the determination of staffing requirements and ends with the specification of the work to be performed, over a particular time period, by each individual in the workforce. Moreover, requirements for different modules depend on their applications:

- Module 1: Demand modelling. The first module in developing a roster is used to determine how many employees are required in different time slots.

- Module 2: The days off scheduling module involves a determination of how rest days should be interspersed between workdays for different lines of work.

- Module 3: The shift scheduling module deals with the problem of selecting, from a potentially large pool of candidates, what shifts are to be worked, together with an assignment of the number of employees.

- Module 4: The line of work construction module involves the creation of lines of work, which are sometimes referred to as work schedules or roster lines, spanning the rostering horizon, for each staff member.

- Module 5: The task assignment module. There may be one or more tasks in each shift and the task may require specific skills; qualifications must be related to specific tasks and must, therefore, be associated with particular lines of work.

- Module 6: The staff assignment module involves assignments for individual staff to their lines of work. Staff assignment is often done during construction of the work lines.

\subsection{Classification of Personnel Scheduling Approaches}

Different shift scheduling results will lead to different rostering strategies [8]. De Causmaecker [9] argued that the rostering problem of companies can be divided into four categories: (1) permanence-centered planning, (2) fluctuation-centered planning, (3) mobility-centered planning, and (4) project-centered planning, where each category has a different operation method (each scheduling method involves a unique planning approach). Among them, permanence-centered and mobility-centered planning can be classified as fixed shift oriented rostering problems. Fluctuation-centered and project-centered planning can be classified as flexible shift-oriented rostering problems. Ernst et al. [7] also argued that rostering problems will have different operational methods due to different shift scheduling results and noted that the development of the mathematical models and algorithms underlying a rostering tool will involve (1) shift scheduling results, (2) government regulations and personnel preferences, and (3) performance goals. In addition, some studies suggest that rostering will have different operational methods due to different employee characteristics, such as full time, part time, casual, skills, individual entities, or crews (team) [10].

The scheduling system of service industry organization is not as simple as that of the general manufacturing industry. The scheduling of the service industry is often a scheduling problem among the members of the service organization and faces many problems, not only regarding the relationship between the work order and the machine.

In addition, the service industry has to deal with scheduling appointments under different allocations of resources, such as predetermined aircraft door allocations, meeting rooms, and facilities. Usually, there will be no MRP (Material Requirement Planning) program in contrast with the manufacturing system scheduling. The service scheduling model used usually considers different 
factors under a different scheduling model. Factors that must be considered typically include staff time provisions. According to the Labor Standards Law, there are a fixed number of hours of work per day; moreover, employees must rest on a regular basis and be given vacations. In addition, because each employee's ability to work is different, companies must assign different people to provide services in a given slot of time. Moreover, some companies' machines require $24 \mathrm{~h}$ operation, so there must always be monitoring personnel at the scene. This will lead to a fairness of scheduling problem that requires managers to coordinate different scheduling decision functions.

According to the classification of the different personnel scheduling problems for companies, different scheduling problems yield different models [9], which are described as follows:

- $\quad$ Permanence-centered planning: This model is usually necessary to define in advance the number of people required for the corresponding personnel, such as police agencies and hospitals.

- Fluctuation-centered planning: This type of personnel planning is based on changing needs, such as those of warehouses or distribution centers, as well as fast-food restaurants and postal units with outbound delivery.

- Mobility-centered planning: This is used when a company's mission involves planning issues related to the movement of traffic, such as for the health and safety boards of mobile care clinics.

- $\quad$ Project-centered planning: This model assigns different employees to different divisions of project planning, such as in software development and consulting and architectural consultant companies.

A comparison of these models is shown in Table 1.

Table 1. Comparison Chart of scheduling problem classifications.

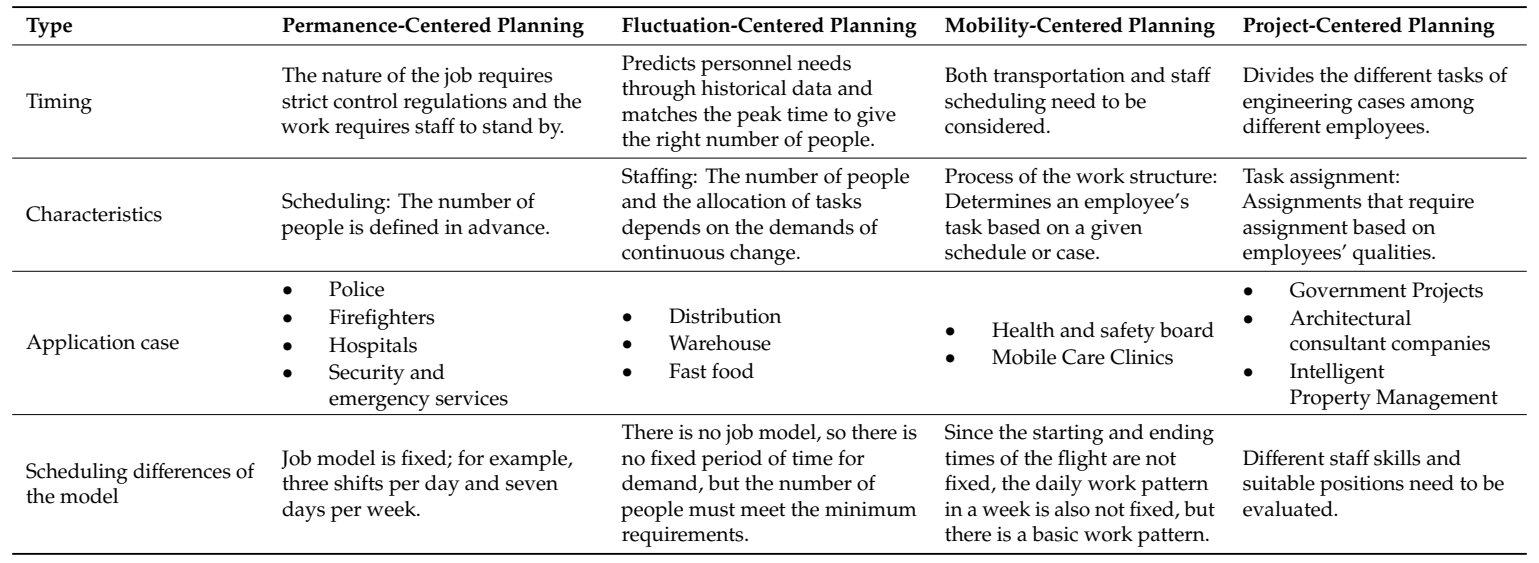

Table 2 provides a summary of recent studies categorized into the four types of personnel scheduling problems.

Table 2. Summary of Personnel Scheduling Problems.

\begin{tabular}{llll}
\hline Researchers/Year & Type & Objective & Factors and/or Approach \\
\hline Jaumard et al. [11] & Permanence-centered planning & $\begin{array}{l}\text { Minimizing numbers of nurses based } \\
\text { on patients }\end{array}$ & Developed a binary integer programming model \\
\hline Wrigt et al. [12] & Permanence-centered planning & Minimizing cost of nurses & Considered legal requirements \\
\hline Henderson et al. [13] & Fluctuation-centered planning & Minimizing waiting time of customers & Developed a heuristic algorithm \\
\hline Örmeci et al. [14] & Fluctuation-centered planning & Maximizing customer satisfaction & Considered the skill requirements of workers \\
\hline Taylor and Huxley [15] & Permanence-centered planning & $\begin{array}{l}\text { Minimizing numbers of workers } \\
\text { based on shift requirements }\end{array}$ & Developed an intelligent system \\
\hline Corominas et al. [16] & Project-centered planning & Minimizing labor costs & Considered skill requirements of each project \\
\hline Mutingi and Mbohwa [17] & Mobility-centered planning & Minimizing costs of healthcare & $\begin{array}{l}\text { Developed a heuristic algorithm and considered } \\
\text { time windows requirements from patients }\end{array}$ \\
\hline Parisio and Jones [18] & Fluctuation-centered planning & Minimizing labor costs & Developed a demand forecasting model \\
\hline
\end{tabular}


Table 2. Cont.

\begin{tabular}{llll}
\hline Researchers/Year & Type & Objective & Factors and/or Approach \\
\hline Bard and Binici [19] & Fluctuation-centered planning & Minimizing labor costs & $\begin{array}{l}\text { Developed an integer programming model and } \\
\text { considered the vacation desired of labors }\end{array}$ \\
\hline Bruni andDetti [20] & Permanence-centered planning & Maximizing labor satisfactions & Developing a mixed integer programming model \\
\hline $\begin{array}{l}\text { Tajimaand and } \\
\text { Misono [21] }\end{array}$ & Fluctuation-centered planning & Minimizing number of labor shifts & $\begin{array}{l}\text { Airline crew-scheduling problem with many } \\
\text { irregular flights }\end{array}$ \\
\hline Stojkovic [22] & Fluctuation-centered planning & $\begin{array}{l}\text { Minimizing total costs and } \\
\text { labor conflicts }\end{array}$ & The operational airline crew scheduling problem \\
\hline Thompson [23] & Permanence-centered planning & $\begin{array}{l}\text { Minimizing labor costs and } \\
\text { maximizing labor satisfaction }\end{array}$ & Developing a two phase model \\
\hline Lezau et al. [24] & Fluctuation-centered planning & Minimizing labor costs & Assigning tasks to different labor \\
\hline Zulch et al. [25] & $\begin{array}{l}\text { Fluctuation-centered planning } \\
\text { Project-centered planning }\end{array}$ & Minimizing labor costs & Developing a simulation model \\
\hline
\end{tabular}

\section{The Case Study}

\subsection{Current Scheduling Procedures and Results}

The scheduling procedures currently adopted by airlines are divided into two stages: monthly planning and daily schedule planning (as shown in Figure 1). A monthly schedule shows all the morning shifts, night shifts, and days off for the staff. The administrative staff responsible for scheduling must consider the human resource demands of each department, as well as individual staff members' priorities for leave-taking. The following figure illustrates the scheduling procedures for a monthly schedule in the airline being studied. First, the personnel and schedule information must be collected before next month's schedule to be planned in the system. From the employees' viewpoint, before a monthly schedule is planned, a staff member must submit a hard copy of an application to apply for annual or compensatory leave. The monthly schedule of the following month is released on the 20th of each month. Staff are allowed three days from the release date to apply for schedule changes. Finally, the monthly schedule is confirmed and updated to the schedule system on the 25th of each month.

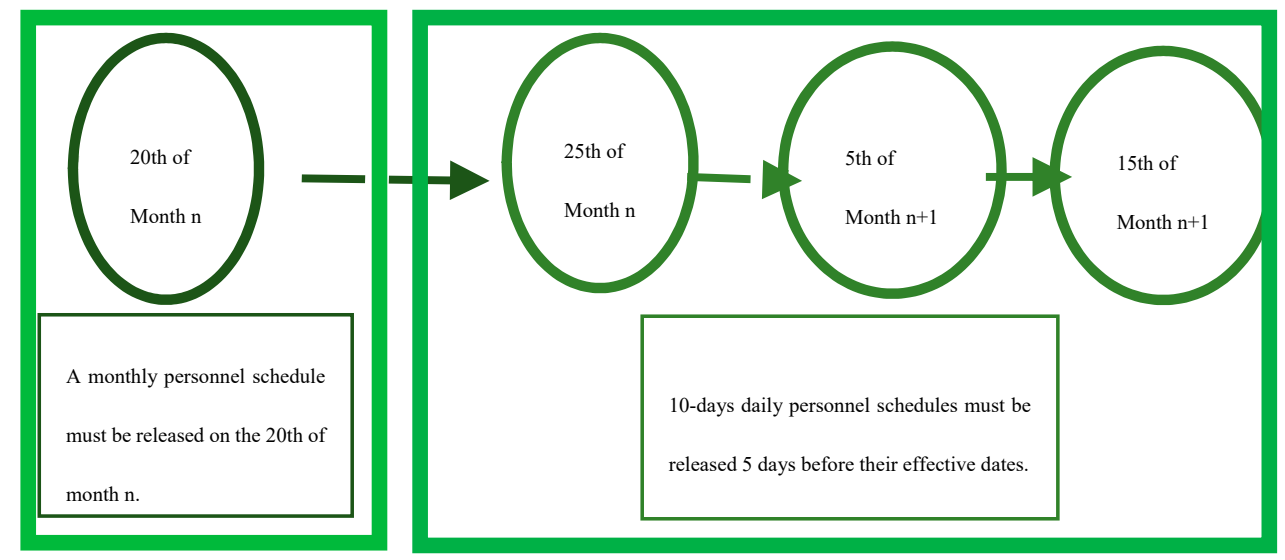

Figure 1. A two phase personnel scheduling workflow.

Monthly schedules are first planned with consideration of each staff member's monthly workdays and weekly work hours; then, the monthly schedule is presented along with the shift codes. The shifts of ground staff are determined primarily by flights and such staff must be highly focused at work, particularly during peak flight hours. Therefore, this airline shortens shifts during peak hours and extends shifts during off-peak hours.

In addition, daily schedules are restricted by monthly schedules and are affected by unexpected situations. For a daily schedule, the human resource demand in each time slot and the appropriate position for each staff member are determined according to the timetable of flights and the number of staff members available in each department. Therefore, staff responsible for scheduling must consider the flight information (monthly shift schedules) and professional abilities of each staff member to 
determine the human resource demand daily before scheduling. Finally, the staff plan daily schedules manually, publish the schedules, and submit them to the personnel department for archiving.

According to the aforementioned scheduling method, this study compiled the differences between daily and monthly schedules in the following table and defined the parameters used in the scheduling process to complete planning of the monthly and daily schedules simultaneously.

\subsection{Defining the Problems of Scheduling Models}

Studies have predominantly classified personnel scheduling problems into four types: permanence-centered planning, fluctuation-centered planning, mobility-centered planning, and project-centered planning; furthermore, each scheduling method involves a unique planning approach [9]. The studied airline adopted fluctuation-centered, mobility-centered, and project-centered planning (see Table 3); therefore, this study aimed to integrate these three planning methods and apply them in their respective suitable areas. Project-centered planning is usually used to assign staff members to job positions, with some staff members able to work concurrently in more than two positions. Fluctuation-centered planning considers the peak and off-peak periods of flights and involves all aspects of the scheduling parameters and variables, with the number of staff members assigned having to meet the minimum number required. In mobility-centered planning, the weekly schedule structure is not fixed, but a basic structure exists. The limitations of mobility-centered planning are delineated in fluctuation-centered planning.

Table 3. Comparison between monthly and daily schedules.

\begin{tabular}{|c|c|c|}
\hline & Monthly Schedule & Daily Schedule \\
\hline Scheduling Goals & $\begin{array}{l}\text { Determining all staff's morning shifts, night } \\
\text { shifts, and days off. } \\
\text { - Considering staff's priorities } \\
\text { for leave-taking. } \\
\text { - Following mandatory regulations in the } \\
\text { Labor Standards Act. } \\
\text { Designing base shifts for the convenience } \\
\text { of scheduling. }\end{array}$ & $\begin{array}{l}\text { - Restricted by monthly schedules and } \\
\text { affected by unexpected situations. } \\
\text { Emphasizes duty assignments conducted } \\
\text { according to individual staff members' } \\
\text { professional abilities. } \\
\text { - Ensures the consideration of flight } \\
\text { information and human resource demands. }\end{array}$ \\
\hline Parameter and Constraints & $\begin{array}{l}\text { - } \quad \text { Mobility-centered planning. } \\
\text { - } \quad \text { Legal regulations and the number of days to } \\
\text { be scheduled. } \\
\text { - Numbers of days and weeks to } \\
\text { be scheduled. } \\
\text { The legal maximum number of workdays } \\
\text { within the period being scheduled and } \\
\text { consecutive workdays for a staff member. } \\
\text { Maximum work hours within a week for a } \\
\text { staff member. }\end{array}$ & $\begin{array}{l}\text { - } \quad \text { Project-centered planning. } \\
\text { - } \quad \text { The specialties of each staff member. } \\
\text { - } \quad \text { The required number of staff members with } \\
\text { a specialty in j for t intervals within d days. }\end{array}$ \\
\hline
\end{tabular}

\section{The Proposed Hybrid Personnel Scheduling Model}

A common concept in personnel rostering treats the following problem: Staff have to be assigned to shifts in a way that satisfies a variety of constraints. These problems are characterized by a set of staff $i=\{1, \ldots, \mathrm{I}\}$, a scheduling period of days $t=\{1, \ldots, \mathrm{T}\}$, and a set of shifts $w=\{1, \ldots, \mathrm{W}\}$.

This study employed mixed-integer programming to solve the scheduling problems for ground staff. Scheduling models are based on staff skills and the demand for staff members in different job positions. The required data were imported and the parameter settings were defined. These data include legal restrictions, the professional skills required in each time slot (obtained through demand forecasting), staff skills, and shift data. Then, mixed-integer programming was used to produce schedules that satisfied all constraints; the major constraints were the human resource demands, legal restrictions, and staff needs. Finally, the daily schedule of each staff member was output with the following solution flow chart (as illustrated in Figure 2) 


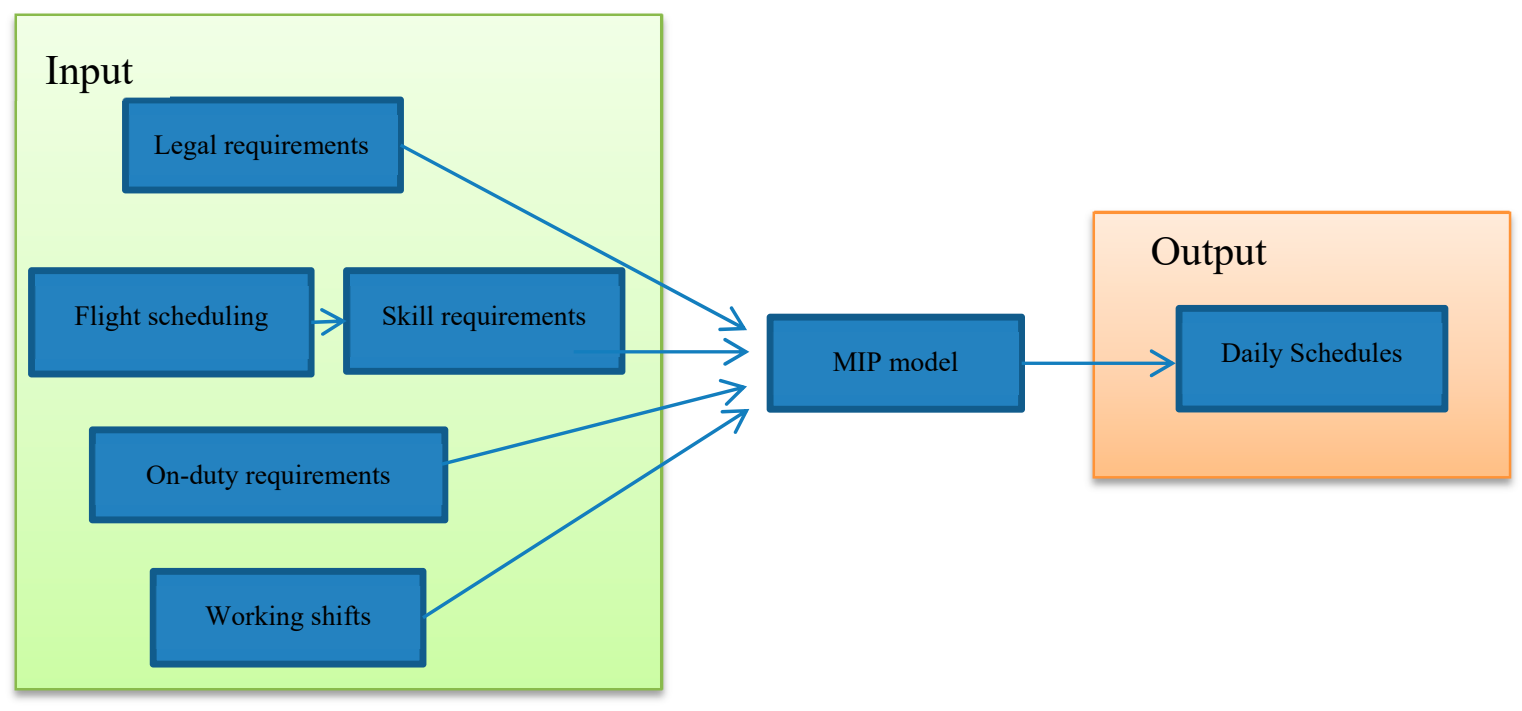

Figure 2. Framework of the mixed integer programming model.

This study firstly reviewed all restrictions on scheduling, particularly those related to flight timetables and staff skills. Subsequently, the restrictions were recategorized and described as follows:

\subsection{Index}

To establish a model with a comprehensive structure and facilitate its application in real-life situations, the following information and symbol descriptions were proposed during the model's construction.

$i$ : a ground staff member whose schedule is being planned, attendant $i$, with a total of $I$ ground staff; $i=1-I$

$j$ : staff skills, with a total of $J$ skills; $j=1-J$

Assumptions:

$j=1$ (administration section)

$j=2$ (baggage section)

$j=3$ (ticket section)

$j=4$ (airport lounge)

$j=5$ (Check-in counter control)

$j=6$ (Check-in counter section)

$w$ : shift $w$, with a total of $W$ shifts; $w=1-W$

\section{Assumptions:}

$$
\begin{aligned}
& w=1(05: 00 \sim 14: 00) \\
& w=2(05: 00 \sim 15: 00) \\
& w=3(05: 00 \sim 16: 00) \\
& w=4(05: 00 \sim 17: 00) \\
& w=5(06: 00 \sim 17: 00) \\
& w=6(08: 00 \sim 17: 00) \\
& w=7(13: 00 \sim 20: 00) \\
& w=8(13: 00 \sim 23: 00) \\
& w=9(13: 00 \sim 24: 00) \\
& w=10(14: 00 \sim 24: 00)
\end{aligned}
$$


$t:$ work period; $\mathrm{t}=1-T$

Assumption: $T=24$

$d$ : day of a planned shift; $d=1-D$

Assumption: $D=28$

\subsection{Parameters}

$o$ : the cost of a staff member being on shift; $o=126$

$r_{j t d}$ : number of staff members with skill $j$ required in work period $t$ on day $d(j \in J, t \in T, d \in D)$.

$p_{i j w}$ : equals 1 if staff member $i$ has skill $j$; equals 0 if not $(i \in I, j \in J, w \in W)$.

$\eta$ : maximum number of staff members each day; $\eta=30$

$\theta$ : maximum number of consecutive workdays for a staff member; $\theta=6$

$\tau_{\text {max }}$ : legal maximum number of workdays within the period being scheduled for a staff member; $\tau_{\max }=21$

$\tau$ : maximum number of workdays that does not cause dissatisfaction for a staff member within the period being scheduled for him or her; $\tau=20$

$\beta$ : maximum number of weekly work hours for a staff member; $\beta=56$

$e_{w t}$ : equals 1 if shift $w$ is included in work period $t$; equals 0 if not $(w \in W, t \in T)$

$h_{w}$ : hours of work periods included in shift $w(w \in W)$

$y_{w 1 w 2}$ : equals 1 if a staff member is concurrently assigned to shift $w 1$ on day $d$ and to shift $w 2$ on day $d$ +1 ; equals 0 if not $\left(w_{1}, w_{2} \in W\right)$.

$m$ : total number of days scheduled; $m=28$

\subsection{Decision Variables}

$x_{i w d}$ : a binary variable representing whether staff member $i$ is assigned to shift $w$ on day $d$ $(i \in I, w \in W, d \in D)$.

\subsection{Auxiliary Variables}

$P_{i j w d}$ : the proportion of work to which staff member $i$ can apply skill $j$ in shift $w$ on day $d(i \in I, j \in J, w \in W, d \in D)$.

$W_{i}$ : a binary variable representing whether staff member $i$ works over $\tau$ days $(i \in I)$.

\subsection{Objective Function}

Minimize: This model is aimed at minimizing scheduling costs.

$$
\sum_{i \in I} \sum_{w \in W} \sum_{d \in D} o \times h_{w} \times x_{i w d}
$$

\subsection{Subject to the Following Constraints}

\subsubsection{Project-Centered Constraints}

The professional skills provided at each time slot on each day must meet the minimum required demand level:

$$
r_{j t d}-\sum_{i \in I} \sum_{w \in W} e_{w t} P_{i j w d} \leq 0 \forall j \in J, t \in T, d \in D .
$$

Determine the job position that a staff member is assigned to during a shift on a certain day:

$$
P_{i j w d} \leq p_{i j w} x_{i w d} \forall i \in I, j \in J, w \in W, d \in D .
$$


The proportion of staff members assigned concurrently to two or more positions must be less than or equal to 1. A staff member on leave will not be assigned to any job position:

$$
\sum_{j \in J} P_{i j w d} \leq x_{i w d d} \forall i \in I, w \in W, d \in D .
$$

Ensure that a staff member is assigned a maximum of one shift a day:

$$
\sum_{w \in W} x_{i z w d} \leq 1 \forall i \in I, d \in D .
$$

\subsubsection{Legal Regulation Constraints}

Cap the consecutive workdays for staff members. In this study, a staff member was required to not work for more than six consecutive days:

$$
\sum_{d=k}^{k+\theta} \sum_{w \in W} x_{i w d} \leq \theta \forall i \in I, k=1,2, \ldots, m-\theta .
$$

Cap consecutive work hours at a maximum of $56 \mathrm{~h}$ for staff members:

$$
\sum_{d=k}^{k+\theta} \sum_{w \in W} h_{w} x_{i w d} \leq \beta \forall i \in I, k=1,2, \ldots, m-\theta .
$$

Insert a mandatory rest time between consecutive shifts for staff members. For example, a staff member who takes a night shift must not be assigned a morning shift on the following day:

$$
x_{i w_{1} d}+x_{i w_{2} d+1} \leq y_{w 1 w 2}+1 \forall i \in I, w_{1}, w_{2} \in W .
$$

\subsubsection{Fluctuation-Centered Constraints}

The scheduled period includes 21 workdays. If a staff member works for more than 20 days, the dissatisfaction variable Wi equals 1 . In this study, $\tau_{\max }=21$ and $\tau=20$ :

$$
\sum_{w \in W} \sum_{d \in D} x_{i w d}-\tau \leq\left(\tau_{\max }-\tau\right) W_{i} \forall i \in I .
$$

\subsubsection{Mobility-Centered Constraints}

The number of seats $(\eta)$ in the work space is used to limit the number of staff members on duty:

$$
\begin{gathered}
\sum_{i \in I} \sum_{w \in W} e_{w t} x_{i w d} \leq \eta \forall t \in T, d \in D \\
x_{i w d}, W_{i} \in\{0,1\} \forall i \in I, \mathrm{w} \in W, d \in D \\
P_{i j w d} \geq 0 \forall i \in I, j \in J, w \in W, d \in D . .
\end{gathered}
$$

\section{Experimental Results}

\subsection{Scheduling Results and Analysis}

In the previous section, the problem definitions were converted into a mathematical model. The mathematical model itself is tested and presented in this section. Pace [26] divided testing into verification and validation. Verification refers to testing whether a mathematical model completely presents all situations involved in a question's definition, whereas validation refers to testing whether 
the calculated results conform to the results expected based on the question's definition. This study used the simplified demand data of an actual schedule to validate the mod.

\subsection{Data and Parameters for the Scheduling Model}

The job positions for ground staff include administration, baggage, tickets, airport lounges, check-in counter control, and check-in counter sections. Six types of professional functions are required from staff in these positions, with the main job responsibilities for each position provided in the following list. This study assumes that the case airline has a total of 35 ground staff members at Kaohsiung International Airport in Taiwan. The allocation of staff in different job positions is shown in Table 4. The administrative staff is responsible for scheduling and assigning appropriate staff to job positions according to their professional skills.

Table 4. Job position of each staff member.

\begin{tabular}{|c|c|c|c|c|c|c|c|}
\hline Staff & Positions & $\begin{array}{l}\text { Administration } \\
\text { Section }\end{array}$ & $\begin{array}{l}\text { Baggage } \\
\text { Section }\end{array}$ & $\begin{array}{l}\text { Ticket } \\
\text { Section }\end{array}$ & $\begin{array}{l}\text { Airport } \\
\text { Lounge }\end{array}$ & $\begin{array}{c}\text { Check-in Counter } \\
\text { Control }\end{array}$ & $\begin{array}{l}\text { Check-in Counter } \\
\text { Section }\end{array}$ \\
\hline & 1 & $\sqrt{ }$ & $\sqrt{ }$ & & & & \\
\hline & 2 & $\sqrt{ }$ & $\sqrt{ }$ & & & & \\
\hline & 3 & $\sqrt{ }$ & $\sqrt{ }$ & & & & \\
\hline & 4 & $\sqrt{ }$ & $\sqrt{ }$ & & & & \\
\hline & 5 & $\sqrt{ }$ & $\sqrt{ }$ & & & & \\
\hline & 6 & $\sqrt{ }$ & $\sqrt{ }$ & & & & \\
\hline & 7 & $\sqrt{ }$ & $\sqrt{ }$ & & & & \\
\hline & 8 & $\sqrt{ }$ & $\sqrt{ }$ & & & & \\
\hline & 9 & & & $\sqrt{ }$ & $\sqrt{ }$ & & \\
\hline & 10 & & & $\sqrt{ }$ & $\sqrt{ }$ & & \\
\hline & 11 & & & $\sqrt{ }$ & $\sqrt{ }$ & & \\
\hline & 12 & & & $\sqrt{ }$ & $\sqrt{ }$ & & \\
\hline & 13 & & & $\sqrt{ }$ & $\sqrt{ }$ & & \\
\hline & 14 & & & $\sqrt{ }$ & $\sqrt{ }$ & & \\
\hline & 15 & & & $\sqrt{ }$ & $\sqrt{ }$ & & \\
\hline & 16 & & & $\sqrt{ }$ & $\sqrt{ }$ & & \\
\hline & 17 & & & $\sqrt{ }$ & $\sqrt{ }$ & & \\
\hline & 18 & & & $\sqrt{ }$ & $\sqrt{ }$ & & \\
\hline & 19 & & & $\sqrt{ }$ & $\sqrt{ }$ & & \\
\hline & 20 & & & & & $\sqrt{ }$ & $\sqrt{ }$ \\
\hline & 21 & & & & & $\sqrt{ }$ & $\sqrt{ }$ \\
\hline & 22 & & & & & $\sqrt{ }$ & $\sqrt{ }$ \\
\hline & 23 & & & & & $\sqrt{ }$ & $\sqrt{ }$ \\
\hline & 24 & & & & & $\sqrt{ }$ & $\sqrt{ }$ \\
\hline & 25 & & & & & $\sqrt{ }$ & $\sqrt{ }$ \\
\hline & 26 & & & & & $\sqrt{ }$ & $\sqrt{ }$ \\
\hline & 27 & & & & & $\sqrt{ }$ & $\sqrt{ }$ \\
\hline & 28 & & & & & $\sqrt{ }$ & $\sqrt{ }$ \\
\hline & 29 & & & & & $\sqrt{ }$ & $\sqrt{ }$ \\
\hline & 30 & & & & & $\sqrt{ }$ & $\sqrt{ }$ \\
\hline & 31 & & & & & $\sqrt{ }$ & $\sqrt{ }$ \\
\hline & 32 & & & & & $\sqrt{ }$ & $\sqrt{ }$ \\
\hline & 33 & & & & & $\sqrt{ }$ & $\sqrt{ }$ \\
\hline & 34 & & & & & $\sqrt{ }$ & $\sqrt{ }$ \\
\hline & 35 & & & & & $\sqrt{ }$ & $\sqrt{ }$ \\
\hline
\end{tabular}


- Administration section: handling passenger irregularities, adjusting human resource allocations in real time, and monitoring on-site flight operations.

- Baggage section: helping passengers collect their baggage and handling cases of passenger baggage irregularities, lost baggage, delayed baggage, stolen baggage, and damaged baggage.

- Ticket section: handling ticket affairs and flight codes.

- Airport lounge (service attendants): providing services to passengers waiting for their flights in the airport lounge, responding to their inquiries, establishing data sheets for passengers in the airport lounge, and managing the files of these sheets.

- Check-in counter control: staff of the counter section are divided into those who control the check-in counters and the counter attendants.

- Check-in counter section: assisting in checking in and the relevant procedures for departing passengers, helping passengers select seats, checking in their baggage, and recording the seats remaining on each flight and then handing over the data to staff on the following shift.

This study assumes that 10 shifts (see Table 5) exist, namely W1-W10; the work period and work hours of each shift were recorded as follows:

Table 5. Work shifts and periods.

\begin{tabular}{ccc}
\hline Shift & Work Period & Work Hours \\
\hline W1 & $5: 00 \sim 14: 00$ & 9 \\
\hline W2 & $5: 00 \sim 15: 00$ & 10 \\
\hline W3 & $5: 00 \sim 16: 00$ & 11 \\
\hline W4 & $5: 00 \sim 17: 00$ & 12 \\
\hline W5 & 6:00 14:00 & 11 \\
\hline W6 & 8:00 14:00 & 9 \\
\hline W7 & 13:00 20:00 & 7 \\
\hline W8 & 13:00 23:00 & 10 \\
\hline W9 & 13:00 24:00 & 11 \\
\hline W10 & 14:00 24:00 & 10 \\
\hline
\end{tabular}

This study imposed a mandatory rest period for staff members between consecutive shifts; for example, a staff member working a night shift was required not to work a morning shift the following day. Table 6 presents the relationships between shifts in terms of whether two shifts could be consecutive; 1 denotes that a shift can follow another and 0 denotes that a shift cannot follow another.

Table 6. Relationships between consecutive shifts.

\begin{tabular}{cccccccccccc}
\hline \hline Shift on the Current Day & $\mathbf{1}$ & $\mathbf{2}$ & $\mathbf{3}$ & $\mathbf{4}$ & $\mathbf{5}$ & $\mathbf{6}$ & $\mathbf{7}$ & $\mathbf{8}$ & $\mathbf{9}$ & $\mathbf{1 0}$ \\
\hline 1 & 1 & 1 & 1 & 1 & 1 & 1 & 1 & 1 & 1 & 1 \\
\hline 2 & 1 & 1 & 1 & 1 & 1 & 1 & 1 & 1 & 1 & 1 \\
\hline 3 & 1 & 1 & 1 & 1 & 1 & 1 & 1 & 1 & 1 & 1 \\
\hline 4 & 1 & 1 & 1 & 1 & 1 & 1 & 1 & 1 & 1 & 1 \\
\hline 5 & 1 & 1 & 1 & 1 & 1 & 1 & 1 & 1 & 1 & 1 \\
\hline 6 & 1 & 1 & 1 & 1 & 1 & 1 & 1 & 1 & 1 & 1 \\
\hline 7 & 0 & 0 & 0 & 0 & 0 & 1 & 1 & 1 & 1 & 1 \\
\hline 8 & 0 & 0 & 0 & 0 & 0 & 1 & 1 & 1 & 1 & 1 \\
\hline 9 & 0 & 0 & 0 & 0 & 0 & 1 & 1 & 1 & 1 & 1 \\
\hline 10 & 0 & 0 & 0 & 0 & 0 & 1 & 1 & 1 & 1 & 1 \\
\hline
\end{tabular}


The schedules of ground staff must be planned with consideration of flight timetables on the premise that the human resource demands have been met. This study assumes that flight times fluctuate in a weekly cycle. Table 7 presents the human resource demands for each position every day.

Table 7. Human resource demands in each position every day.

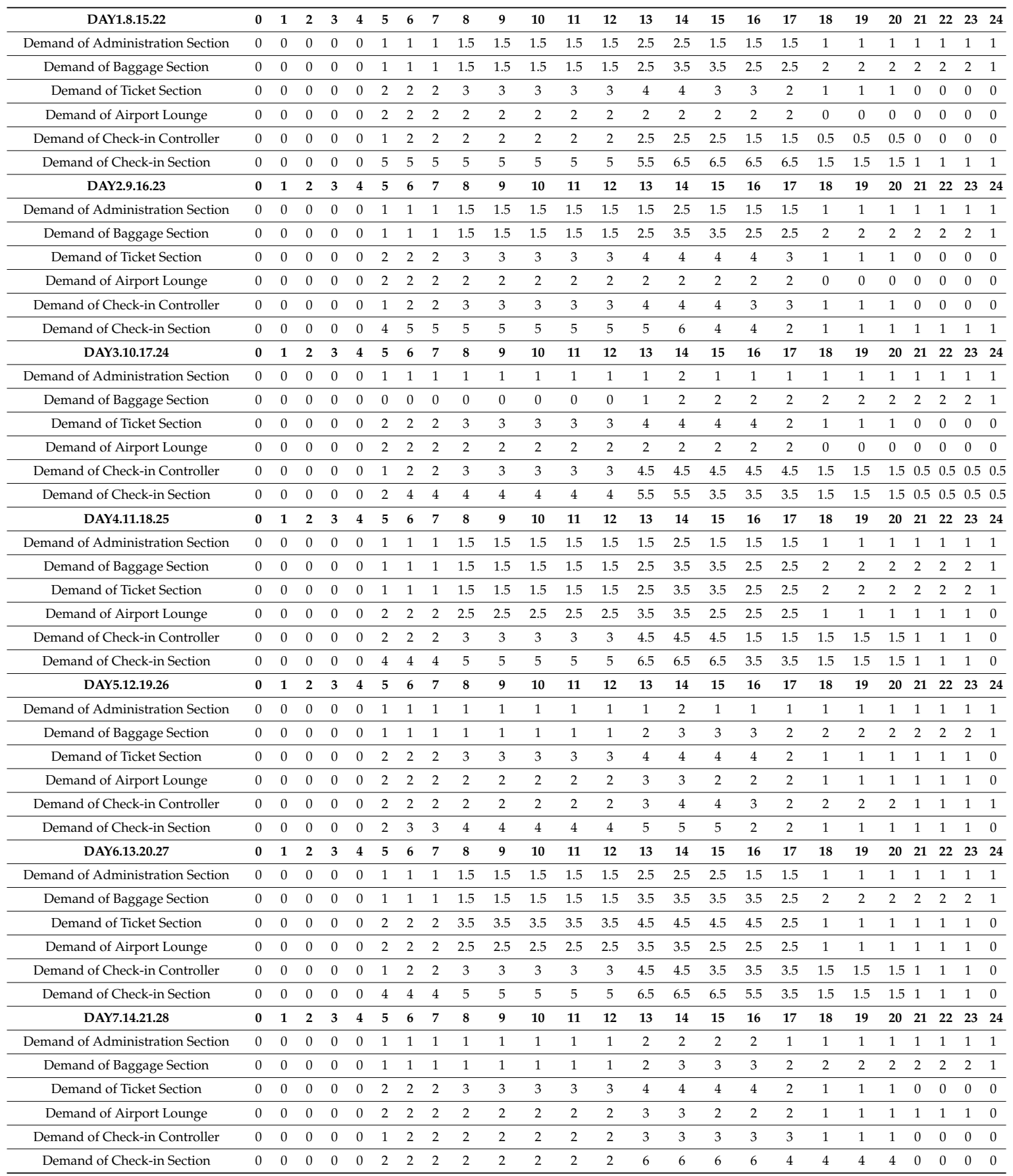

\subsection{Sub-Conclusion}

This study adopted mixed-integer programming as its mathematical model and used the Lingo 13.0 software package to determine the relevant solutions. The aforementioned mathematical model was converted into Lingo programs; the parameters (e.g., staff skills, demand forecasts for flights, and penalty coefficients determined according to staff dissatisfaction) were likewise imported into Lingo programs through Excel. The schedules of the ground staff were planned impartially; the staff 
were assigned to positions according to the optimal solution. When external constraints change or must be modified, this model allows the constraint equations to be altered according to changes in the model. The optimal feasible solutions obtained can provide references for staff responsible for scheduling the assignment of other staff.

\subsection{Results Analysis}

Model output setting: Before Lingo 13.0 was used to find the model solution, the limit was increased to 50,000 through the General Memory Limit under Options to facilitate a smooth solution-finding process.

(1) Model output: The model solution was found using the Lingo 13.0 optimization program. Figure 3 presents the Lingo solution-finding result screen.

(2) Numbers of decision variables and constraint equations:

Number of decision variables: 77,049 ;

Number of constraint equations: 84,680 ;

Model efficiency:

Number of solution-finding cycles: 547,169;

Number of solution-finding steps: 87 ;

Time used to solve the model: $30 \mathrm{~min}$ and $14 \mathrm{~s}$.

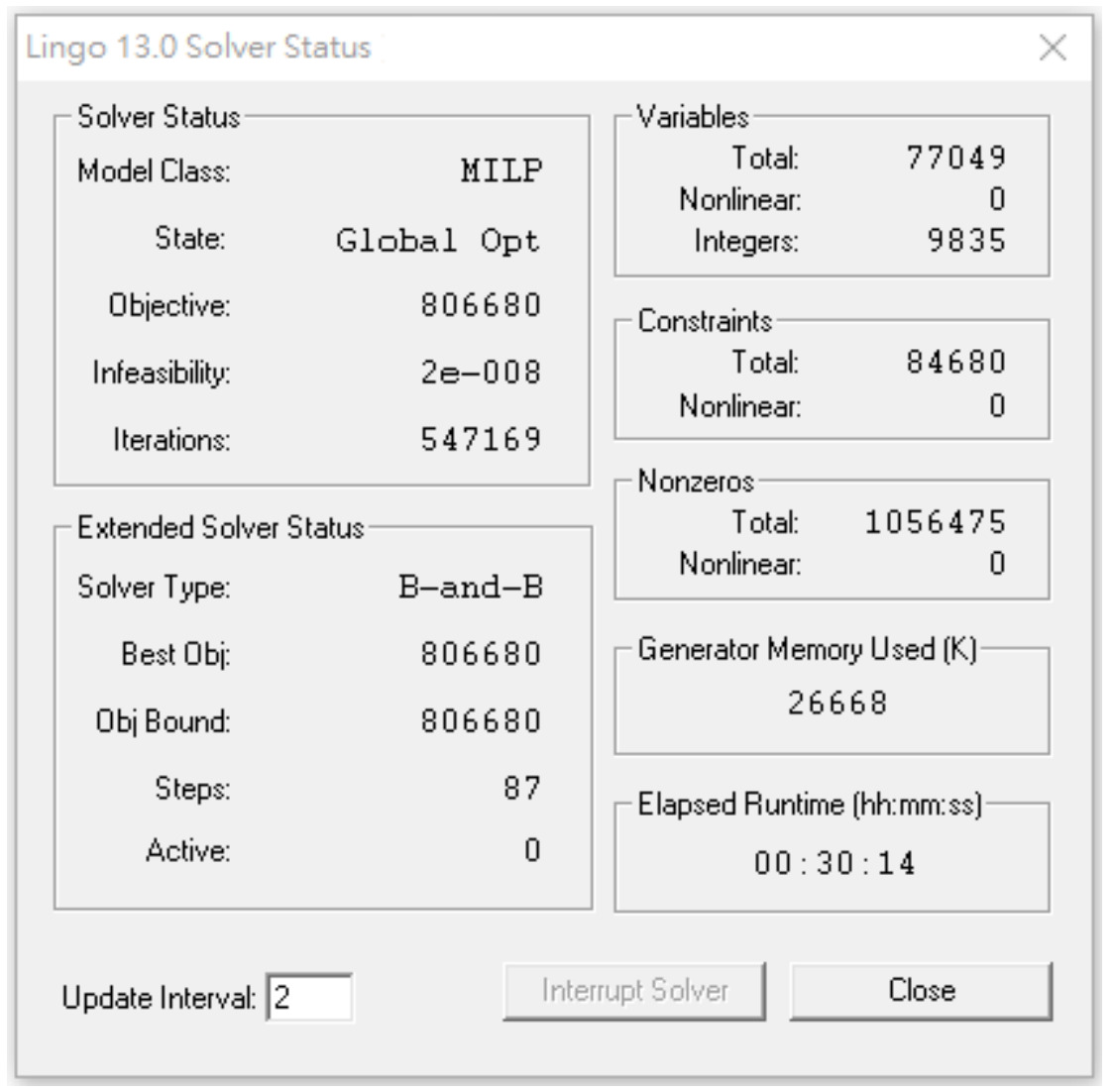

Figure 3. Screen of the solution output by Lingo.

This study investigated the optimal human resource allocation for ground staff using Excel to extract the output Lingo files and convert them. After the Lingo output was converted into an Excel sheet, the following results were obtained: the time slots scheduled for each ground staff member, the number of job positions assigned to that member, and the objective value. Figure 4 presents the 
optimal allocation results for a 28 day period, where the rows denote days and the columns denote staff members. The cells are filled with the code of the shift that each staff member is taking on the current day and blank cells are days off. The proposed model successfully incorporates legal restrictions into the model constraints. For example, these constraints require that each staff member must not work more than 20 days a month, 56 consecutive hours, or 6 consecutive days; each staff member should be assigned continuous rest time; and staff members working the last shift of the day must not work the first shift the following day.

\begin{tabular}{|c|c|c|c|c|c|c|c|c|c|c|c|c|c|c|c|c|c|c|c|c|c|c|c|c|c|c|c|c|}
\hline $\begin{array}{l}\text { Day } \\
\text { Staff }\end{array}$ & 1 & 2 & 3 & 4 & 5 & 6 & 7 & 8 & 9 & 10 & 11 & 12 & 13 & 14 & 15 & 16 & 17 & 18 & 19 & 20 & 21 & 22 & 23 & 24 & 25 & 26 & 27 & 28 \\
\hline 1 & & 10 & & & 1 & 6 & 8 & 1 & & 10 & & 1 & 2 & 3 & 2 & & 10 & & & 6 & 3 & 8 & & 1 & 10 & & 9 & \\
\hline 2 & 2 & 10 & 1 & & 10 & 9 & & 2 & 2 & & 2 & 3 & & 3 & 9 & & 10 & & 1 & 2 & 8 & & 2 & & 2 & 10 & 2 & 9 \\
\hline 3 & 6 & 1 & & 10 & & 3 & 3 & 9 & & 10 & 10 & & 6 & 10 & & 1 & 8 & 6 & & 3 & & 9 & 8 & 8 & & 8 & 3 & \\
\hline 4 & 10 & 8 & & 8 & 3 & 6 & & 8 & 6 & & 6 & & 3 & 8 & 6 & 6 & & 2 & & 9 & 9 & 10 & 6 & & 1 & & 6 & 3 \\
\hline 5 & 9 & & 10 & 10 & & 2 & 3 & & 10 & 1 & 8 & & 9 & & & 2 & 1 & 10 & 3 & \begin{tabular}{|l|}
8 \\
\end{tabular} & & & 1 & 10 & 6 & 1 & 9 & \\
\hline 6 & & 2 & & 1 & 8 & & 10 & 6 & 10 & & 10 & 10 & & 9 & 10 & 10 & & 10 & 10 & & 3 & 6 & & 10 & & & 8 & 8 \\
\hline 7 & 1 & & 10 & & 10 & 9 & 9 & & 8 & 8 & & 8 & 8 & & 1 & 10 & & 8 & 8 & & 10 & 2 & 10 & & 10 & 10 & & 10 \\
\hline 8 & 8 & 6 & 8 & 2 & & 8 & & 10 & 1 & & 1 & 10 & 9 & & 8 & 8 & & 1 & 10 & 9 & & 1 & 10 & & 8 & 3 & & 3 \\
\hline 9 & & 3 & & 1 & 1 & 6 & & 3 & 4 & & & 4 & & 3 & 4 & & 3 & & 3 & 8 & 1 & 4 & & 6 & & 3 & 6 & 4 \\
\hline 10 & & 4 & 4 & 8 & & 1 & 8 & & 3 & 4 & 6 & & & 4 & & 4 & & 2 & 3 & 3 & & & 4 & & & 6 & 4 & 3 \\
\hline 11 & 1 & & 4 & 8 & & 8 & 3 & & 4 & & 8 & & 3 & 1 & 4 & 4 & & & 8 & 3 & & & & $\begin{array}{l}4 \\
\end{array}$ & 8 & 8 & 1 & 3 \\
\hline 12 & 4 & 6 & 3 & & 4 & & & 1 & 6 & & & 1 & 3 & 7 & 1 & 4 & & & 8 & & 3 & 1 & 4 & & 6 & & & 1 \\
\hline 13 & 4 & & 7 & & 8 & 4 & 4 & 7 & & & & 6 & 1 & & 6 & 3 & 7 & 8 & 1 & & 7 & 3 & & 3 & 4 & & 8 & \\
\hline 14 & 7 & & & & 8 & & 7 & & & 7 & & 8 & 8 & & & & 6 & 8 & & 6 & 3 & & 4 & 3 & 2 & & & 7 \\
\hline 15 & & 4 & 3 & 4 & 6 & 3 & & & & 6 & 10 & 8 & 6 & 8 & 7 & & & 1 & & 1 & & & 7 & 7 & & 3 & 3 & \\
\hline 16 & 6 & 4 & & 10 & 3 & & 1 & 6 & & 4 & 2 & & 4 & & & 7 & 4 & 6 & & & & 7 & 3 & & 1 & 8 & 3 & \\
\hline 17 & 3 & 7 & & 6 & & 8 & 3 & 4 & & 3 & 4 & & 6 & 3 & 3 & & 4 & & 6 & 8 & 8 & 4 & & & 10 & 1 & & \\
\hline 18 & & & 6 & 2 & & 3 & & 4 & 4 & & 8 & 3 & 8 & & & & 3 & 10 & & 6 & 4 & 6 & & 4 & 8 & & 8 & 6 \\
\hline 19 & & & & & 3 & 6 & 6 & & 7 & 3 & 1 & 3 & & 6 & & 6 & & 4 & 4 & 4 & 6 & & 6 & & & 4 & 6 & 8 \\
\hline 20 & 4 & & 6 & 2 & 2 & 2 & & 2 & & 1 & 4 & 2 & & 3 & & 6 & 5 & 6 & & 3 & 7 & & & 1 & 2 & & 2 & 4 \\
\hline 21 & & 3 & 7 & 8 & 2 & & 5 & & 2 & 1 & 2 & & 2 & 7 & & & 5 & 2 & 2 & 2 & 7 & & & & 2 & & 3 & 3 \\
\hline 22 & 4 & 3 & 5 & & & 3 & 3 & 4 & & 7 & 2 & & 5 & 4 & & 1 & & 2 & 2 & 5 & & & 1 & 7 & 2 & & 6 & \\
\hline 23 & & 1 & & 4 & & 2 & & 4 & 5 & & 8 & & & 7 & 4 & & 9 & 2 & 3 & & & 4 & 3 & 6 & 8 & 5 & & \\
\hline 24 & 2 & & & 6 & & & & 4 & 1 & & 11 & & & 7 & 4 & 7 & & 8 & & 2 & 4 & 5 & & 1 & & 8 & 4 & 3 \\
\hline 25 & 5 & & 7 & 2 & & 3 & & 4 & 6 & 4 & & 2 & 3 & & 4 & 2 & & & & & 7 & 4 & 10 & & & 2 & 7 & 7 \\
\hline 26 & & 1 & 1 & 2 & 10 & & 7 & & 10 & & & & 8 & 7 & 4 & 5 & 5 & & & 6 & 7 & 4 & 3 & & & 3 & 8 & 7 \\
\hline 27 & 4 & 7 & 5 & & & 7 & 7 & & & 7 & 8 & & 2 & & 4 & 1 & & 7 & & 7 & 3 & 4 & 5 & & 7 & & & \\
\hline 28 & 4 & 5 & 1 & & 8 & 6 & & & 3 & 9 & 2 & 10 & & 3 & & 3 & 4 & 2 & 7 & & & & & 4 & 8 & & 8 & \\
\hline 29 & & & 9 & 8 & 7 & 8 & 3 & & & 5 & 7 & 8 & & & 7 & & 1 & 6 & 5 & & & 2 & 1 & 5 & 6 & 10 & & \\
\hline 30 & & & & 2 & 5 & 4 & & 5 & & 5 & 6 & 7 & 8 & & & & & & 10 & 3 & & 4 & 7 & & 6 & & & \\
\hline 31 & 7 & 6 & 5 & & 6 & 5 & & 10 & 3 & 6 & & 5 & 7 & & 10 & 3 & & 2 & 8 & 6 & & & 2 & 7 & 2 & 6 & 2 & \\
\hline 32 & 4 & & & 7 & 5 & 8 & 7 & 4 & & & 2 & 6 & 6 & & 2 & & 7 & & 2 & 8 & 3 & & 5 & 9 & & 7 & & 7 \\
\hline 33 & & 2 & & 2 & 2 & 6 & 7 & & 5 & & & 3 & 3 & 5 & 5 & & 6 & & 5 & 4 & 5 & & 6 & 5 & & 3 & 3 & 5 \\
\hline 34 & 10 & 5 & & 6 & 3 & & 7 & 7 & 1 & 5 & & 2 & 6 & 7 & & 10 & 7 & 4 & & 8 & 7 & 10 & & & 2 & 2 & 5 & 7 \\
\hline 35 & & 10 & 4 & & & & 4 & & 7 & & 6 & 5 & 4 & & & 5 & 1 & 8 & 6 & & & 7 & & 5 & 4 & 2 & 6 & 7 \\
\hline
\end{tabular}

Figure 4. Monthly schedule output.

Next, the optimal daily schedule in Figure 5 was compared with the actual daily schedule in Figure 6. In the optimal daily schedule, the human resource allocation satisfied the human resource demands of each job position in each time slot. When a single staff member was concurrently required in two job positions, the proportion of job responsibilities assigned was adjusted to enable him or her to work concurrently in both positions. Additionally, this model limited the maximum number of shifts taken by each staff member to one per day. Compared with traditional manual scheduling, the proposed method for optimal schedule production did not require two-stage planning (for monthly and daily schedules). The process involved in manual scheduling is complex. The staff responsible for scheduling must first include the predicted human resource demands and the arrival and departure times of flights into the planning of daily schedules. Subsequently, they can assign employees to job positions according to the flight timetable. The times required by each method were compared, revealing that the proposed scheduling model required $30 \mathrm{~min}$ to find the optimal solution, whereas manual scheduling usually requires $240 \mathrm{~min}$ to do the same. Thus, the proposed scheduling model saved approximately $3.5 \mathrm{~h}$ compared with traditional manual scheduling. Accordingly, the proposed scheduling model is 
practical and accurate. Specifically, the initial model settings were met and the model's output data also represented the optimal human resource allocation.

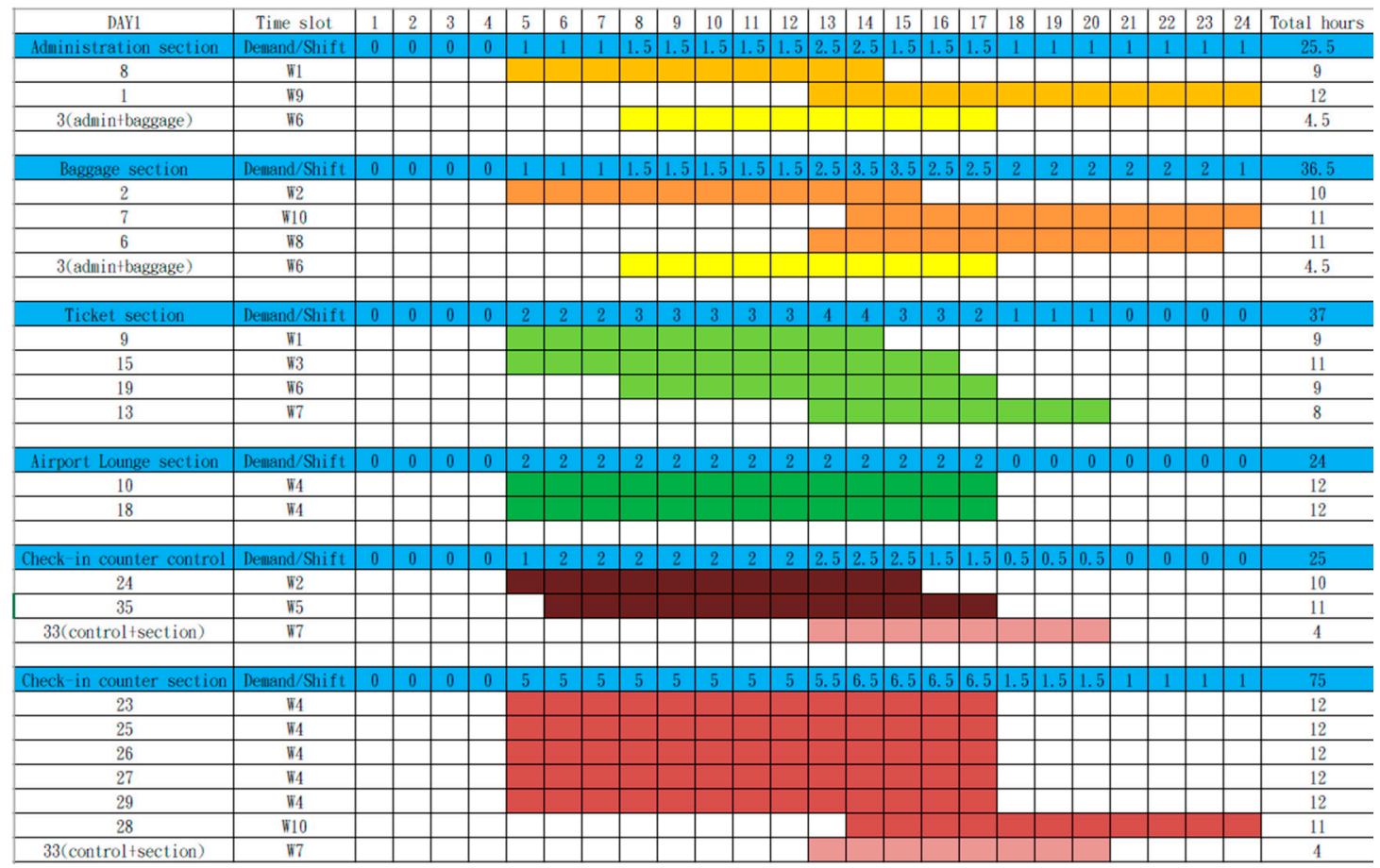

Figure 5. Daily schedule output.

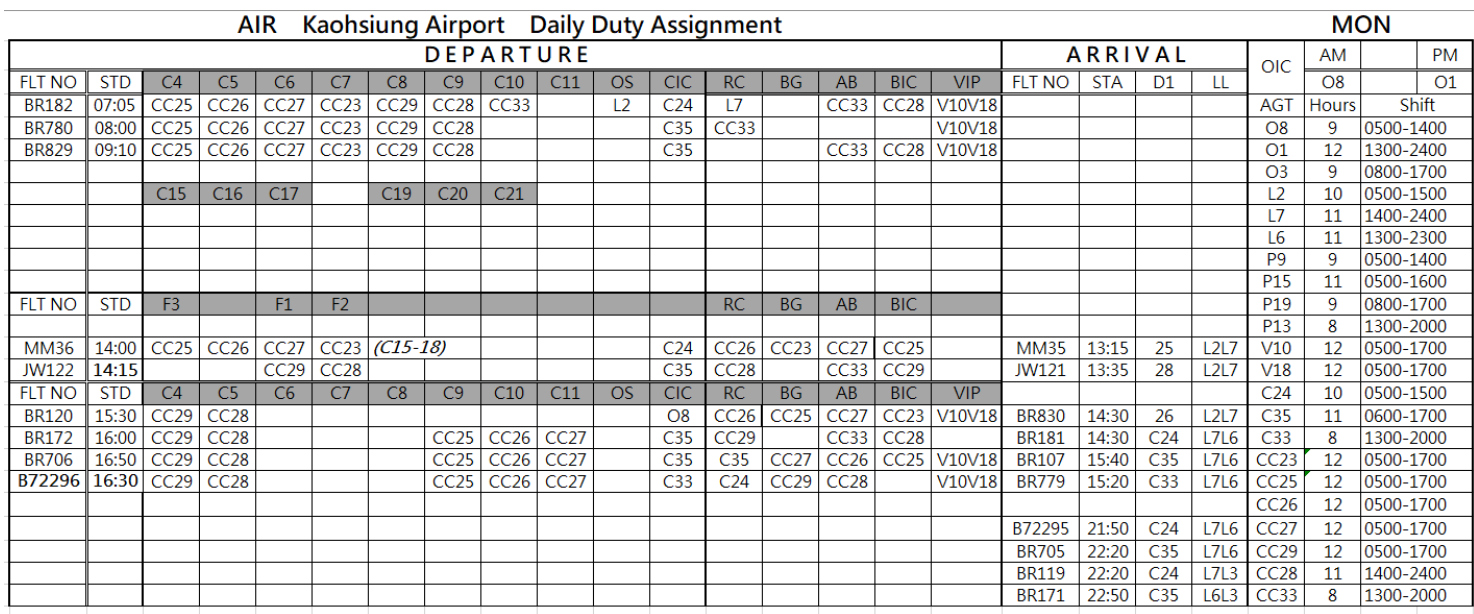

Figure 6. Actual results of the job position allocation in a daily schedule.

\subsection{Proposed Model for Simulation}

To quantify the numbers of ground staff in the case study, the effect of each parameter on the model results was investigated. This analysis aims to facilitate the ability of the staff responsible for scheduling to consider the scope of the effects exerted by various parameters according to the extent to which those parameters affect the objective value of human resource costs in scheduling for the ground staff. This study conducted a simulation analysis of the proposed model with a focus on the parameters in Section 3. The two analyses were performed as follows:

1. Simulation analysis of the variation in the number of ground staff: The number of ground staff must be set according to the actual number of staff demanded based on past experience. Therefore, this section discusses the objective value differences when the number of ground staff members 
required in each position changes (the total number of staff members was initially set to 35 in the model). The initial setting of the model was as follows: Eight staff members were allocated to the administration and baggage sections; 11 to the ticket section and airport lounge; and 16 to the check-in counter control and the check-in counter section. Assuming that the total number of staff members varied by $-3,+3$, and +5 , with the related constraints adjusted, this study analyzed the objective value differences when the number of staff members allocated to the departments changed (as shown in Figure 7 and Table 8). According to the results, when the total number of staff members was increased to 38 or 40 with the same total number of work hours, the objective value of the hourly cost was 806,680 , which confirmed the functionality of the model in actual scheduling. When the total number of staff members was reduced to 32, the workload for ground staff exceeded the weekly maximum; therefore, the results could not be obtained. Specifically, when the total number of ground staff members was less than 32 , the ground staff would not be able to manage the workload.

2. A simulation analysis of the number of staff members required in each time slot is presented: The number of ground staff allocated to each position must be increased or decreased according to the flight situation of the current day. Therefore, considering an identical number of staff members with each professional skill, this section presents a sensitivity analysis of the number of staff members required for each of the six skills (the ability to work in the administration, baggage, tickets, airport lounge, check-in counter control, and check-in counter sections). The analysis was conducted considering the number of staff members demanded $\left(r_{j t d}\right)$ in each time slot on each day, varying by $-1,-0.5,0,+0.5$, and +1 . The analysis results revealed that when the number of staff members required decreased by 0.5 and 1 in each time slot and for each skill, the objective value of the hourly cost was reduced. In contrast, when the number of staff members required increased by 0.5 and 1 in each time slot for each skill, the human resource demands were not met and thus, no solution was found (as shown in Figure 8 and Table 9). Therefore, the result of the simulations can help the staff responsible for scheduling decide whether the human resource demands have been satisfied, which directly affects the smooth functioning of an operational unit.

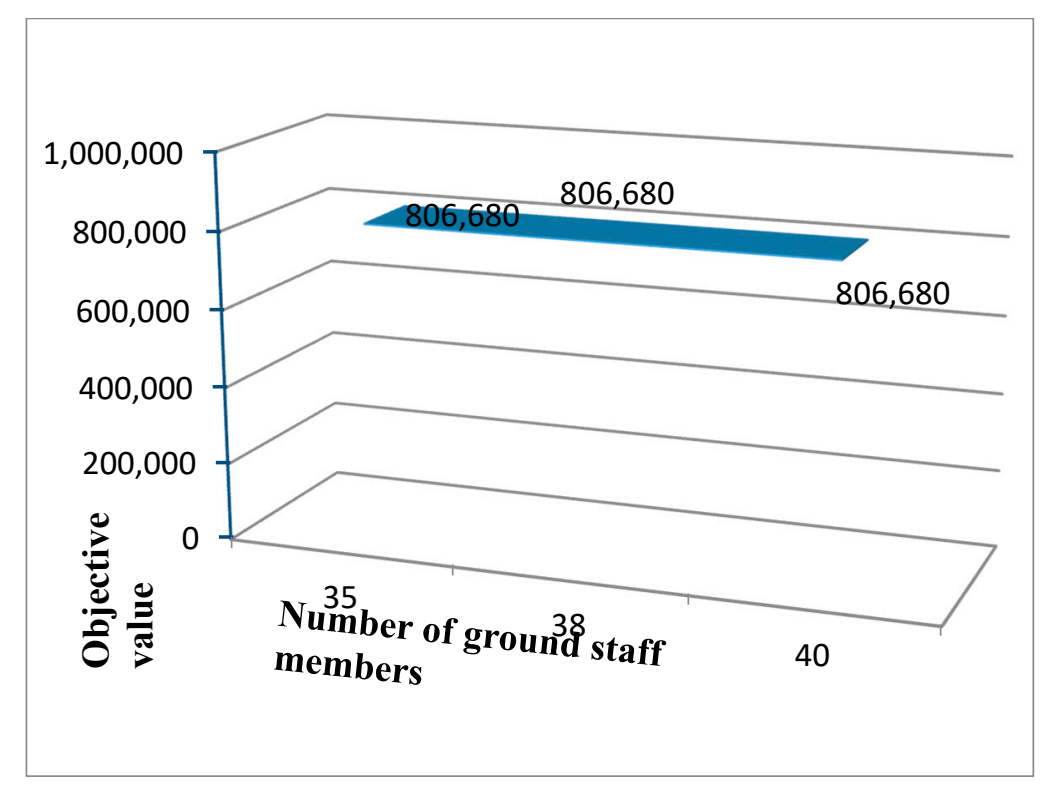

Figure 7. Simulation analysis of the variation in the number of ground staff members. 


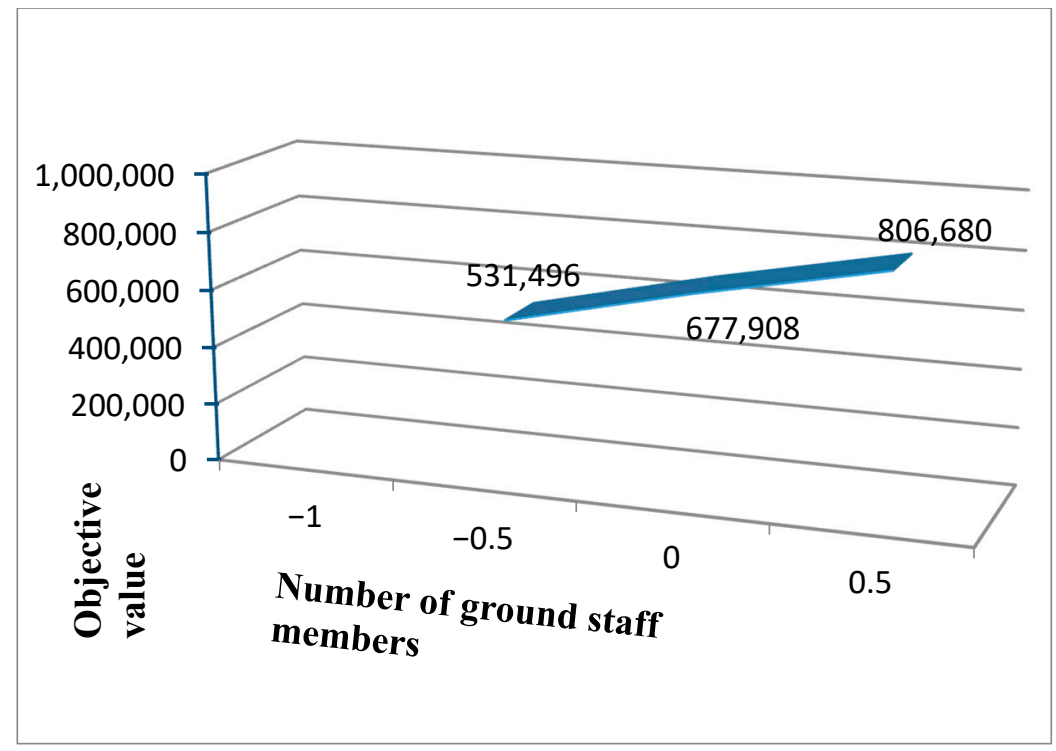

Figure 8. Simulation analysis of the number of staff members required in each time slot.

Table 8. Simulation analysis of the variation in the number of ground staff members.

\begin{tabular}{ccccc}
\hline Variation in the number of ground staff members & -3 & 0 & +3 & +5 \\
Number of ground staff members & 32 & 35 & 38 & 40 \\
Objective value & No solution & 806,680 & 806,680 & 806,680 \\
\hline
\end{tabular}

Table 9. Simulation analysis of the number of staff members required in each time slot.

\begin{tabular}{cccccc}
\hline Variation in the number of ground staff members & -1 & -0.5 & 0 & +0.5 & +1 \\
\hline Objective value & 531,496 & 677,908 & 806,680 & No solution & No solution \\
\hline
\end{tabular}

\section{Conclusions and Suggestions}

\subsection{Conclusions}

To design a hybrid personnel scheduling model, the staff rostering procedure and requirements of a real-world case were first studied. To improve the current rigid approach, the integration of monthly and daily scheduling processes was suggested. An MIP model was designed to generate ground staff schedules. This model combines the traditional three types of personnel scheduling problems, which is not only suitable for ground staff in the aviation industry, but also provides a reference model for other scholars.

By giving the total number of staff, the staff scheduling objectives of this study will consider the minimum "manpower requirements for each period" and the "manpower costs" so that the scheduling results can not only meet the demands, but also minimize the cost of manpower.

The proposed model can also serve as a simulation model for decision making support. By setting different parameters, such as the number of total staff and/or the number of required staff in each time slot, this model helps decision makers not only generate the scheduling results, but also provide their associated costs.

\subsection{Suggestions}

This study model did not take some factors into consideration, such as (1) meal and rest times and (2) employee satisfaction in terms of not having precise vacation days; moreover, (3) only the maximum number of working days was set, not the minimum. The follow-up model will be improved and more user-friendly by considering these factors. 
Author Contributions: Conceptualization, J.-Y.S.; methodology, C.-Y.H.; validation, M.-K.H.; formal analysis, C.-Y.H.; data curation, J.-Y.S.; writing-original draft preparation, J.-Y.S.; writing-review and editing, J.-Y.S.; visualization, M.-K.H.; supervision, J.-Y.S.; funding acquisition, J.-Y.S. All authors have read and agreed to the published version of the manuscript.

Funding: This research is partially supported by the Ministry of Science and Technology, Taiwan under the grant MOST 105-2221-E-327-034.

Conflicts of Interest: The authors declare no conflict of interest.

\section{References}

1. Dawid, H.; König, J.; Strauss, C. An enhanced rostering model for airline crews. Comput. Oper. Res. 2001, 28, 671-688. [CrossRef]

2. Defraeye, M.; Van Nieuwenhuyse, I. Staffing and scheduling under nonstationary demand for service: A literature review. Omega 2016, 58, 4-25. [CrossRef]

3. Chu, S.C. Generating, scheduling and rostering of shift crew-duties: Applications at the Hong Kong International Airport. Eur. J. Oper. Res. 2007, 177, 1764-1778. [CrossRef]

4. Abernathy, W.J.; Baloff, N.; Hershey, J.C.; Wandel, S. A Three-Stage Manpower Planning and Scheduling Model-A Service-Sector Example. Oper. Res. 1973, 21, 693-711. [CrossRef]

5. Mattia, S.; Rossi, F.; Servilio, M.; Smriglio, S. Staffing and scheduling flexible call centers by two-stage robust optimization. OMEGA Int. J. Manag. Sci. 2017, 72, 25-37. [CrossRef]

6. Morris, J.G.; Showalter, M.J. Simple Approaches to Shift, Days-Off and Tour Scheduling Problems. Manag. Sci. 1983, 29, 942-950. [CrossRef]

7. Ernst, A.; Jiang, H.; Krishnamoorthy, M.; Sier, D. Staff scheduling and rostering: A review of applications, methods and models. Eur. J. Oper. Res. 2004, 153, 3-27. [CrossRef]

8. Karam, A.; Attia, E.-A.; Duquenne, P. A MILP model for an integrated project scheduling and multi-skilled workforce allocation with flexible working hours. IFAC-PapersOnLine 2017, 50, 13964-13969. [CrossRef]

9. De Causmaecker, P.; Demeester, P.; Berghe, G.V.; Verbeke, B. Analysis of real-world personnel scheduling problems. In Proceedings of the 5th International Conference on Practice and Theory of Automated Timetabling, Pittsburgh, PA, USA, 18-20 August 2004; pp. 183-197.

10. Bergh, J.V.D.; Belien, J.; De Bruecker, P.; Demeulemeester, E.; De Boeck, L. Personnel scheduling: A literature review. Eur. J. Oper. Res. 2013, 226, 367-385. [CrossRef]

11. Jaumard, B.; Semet, F.; Vovor, T. A generalized linear programming model for nurse scheduling. Eur. J. Oper. Res. 1998, 107, 1-18. [CrossRef]

12. Wright, P.D.; Bretthauer, K.M.; Côté, M.J. Reexamining the Nurse Scheduling Problem: Staffing Ratios and Nursing Shortages*. Decis. Sci. 2006, 37, 39-70. [CrossRef]

13. Henderson, S.; Mason, A.; Ziedins, I.; Thomson, R. A Heuristic for Determining Efficient Staffing Requirements for Call Centres; Technical Report; Department of Engineering Science, University of Auckland: Auckland, New Zealand, 1999.

14. Örmeci, E.L.; Salman, F.S.; Yücel, E. Staff rostering in call centers providing employee transportation. Omega 2014, 43, 41-53. [CrossRef]

15. Taylor, P.E.; Huxley, S.J. A Break from Tradition for the San Francisco Police: Patrol Officer Scheduling Using an Optimization-Based Decision Support System. Interfaces 1989, 19, 4-24. [CrossRef]

16. Corominas, A.; Pastor, R.; Rodríguez, E. Rotational allocation of tasks to multifunctional workers in a service industry. Int. J. Prod. Econ. 2006, 103, 3-9. [CrossRef]

17. Mutingi, M.; Mbohwa, C. Home Health Care staff scheduling. In Proceedings of the IAENG Transactions on Engineering Sciences; Informa UK Limited: London, UK, 2014; pp. 215-224.

18. Parisio, A.; Jones, C.N. A two-stage stochastic programming approach to employee scheduling in retail outlets with uncertain demand. Omega 2015, 53, 97-103. [CrossRef]

19. Bard, J.F.; Binici, C. Staff scheduling at the United States postal service. Comput. Oper. Res. 2003, 30, 745-771.

20. Bruni, R.; Detti, P. A flexible discrete optimization approach to the physician scheduling problem. Oper. Res. Health Care 2014, 3, 191-199. [CrossRef]

21. Tajima, A.; Misono, S. Airline crew-scheduling problem with many irregular flights. Haptics Sci. Technol. Appl. 1997, 1350, 2-11. 
22. Stojkovic, M.; Soumis, F.; Desrosiers, J. The Operational Airline Crew Scheduling Problem. Transp. Sci. 1998, 32, 232-245. [CrossRef]

23. Thompson, G.M. Labor staffing and scheduling models for controlling service levels. Naval Res. Logist. 1997, 44, 719-740. [CrossRef]

24. Lezaun, M.; Pérez, G.; de la Maza, E.S. Crew rostering problem in a public transport company. J. Oper. Res. Soc. 2006, 57, 1173-1179. [CrossRef]

25. Zülch, G.; Rottinger, S.; Vollstedt, T. A simulation approach for planning and re-assigning of personnel in manufacturing. Int. J. Prod. Econ. 2004, 90, 265-277. [CrossRef]

26. Pace, D.K. Modeling and simulation verification and validation challenges. Johns Hopkins APL Technical Digest. Appl. Phys. Lab. 2004, 25, 163-172.

(C) 2020 by the authors. Licensee MDPI, Basel, Switzerland. This article is an open access article distributed under the terms and conditions of the Creative Commons Attribution (CC BY) license (http://creativecommons.org/licenses/by/4.0/). 